Recepción: 26 / 11 / 2016

Aceptación: 25 / 05 / 2017

Publicación: 27 / 07 / 2017
Ciencias de la salud Artículo de investigación

\title{
Consideraciones actuales acerca de la lactancia materna
}

\section{Current considerations about breastfeeding}

\section{Atuais considerações sobre amamentação}

\author{
Marcelino R. Carrasco-Guaman ${ }^{\text {}}$ \\ rafaelcarrasco2688@gmail.com \\ Luís A. Jimbo-Yepez " \\ dr.luisy@hotmail.com \\ Julio C. Jimbo-Mendoza 프 \\ juliojimbom@hotmail.com
}

Correspondencia: rafaelcarrasco2688@gmail.com

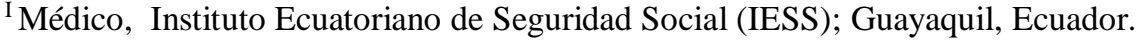

"Médico, Instituto Ecuatoriano de Seguridad Social (IESS); Guayaquil, Ecuador.

"Magister en Gerencia de Salud para el Desarrollo Local, Especialista en Gerencia y Planificación Estratégica en Salud, Doctor en Odontología, Diplomado Superior en Odontología Integral, Diploma Superior en Desarrollo Local y Salud, Docente de La Universidad Laica Eloy Alfaro de Manabí., Manta, Ecuador.
} 


\section{Resumen}

Se comunica brevemente acerca de la lactancia, como el proceso único que proporciona la alimentación ideal para el lactante, que contribuye a la disminución de la morbilidad y mortalidad materna e infantil, establece el vínculo afectivo entre madre-hijo o hija, proporciona beneficios sociales y económicos a la familia y a las naciones. Asimismo se ofrecen resultados de estudios sobre el tema.

Palabras clave: lactancia materna exclusiva; inmunidad.

\section{Abstract}

It briefly communicates about breastfeeding, as the single process that provides the ideal feeding for the infant, which contributes to the reduction of maternal and infant morbidity and mortality, establishes the affective bond between mother and child, provides social and economic benefits to the family and to the nations. Results of studies on the subject are also provided.

Keywords: exclusive breastfeeding; immunity.

\section{Resumo}

Ele brevemente informado sobre a amamentação, como o único processo que fornece a solução ideal para a criança, contribuindo para a diminuição da morbidade e comida mortalidade materna e infantil, define o vínculo emocional mãe-filho e filha, proporciona benefícios sociais e econômicos família e nações. Também os resultados de estudos sobre o tema são oferecidos.

Palavras chave: aleitamento materno exclusivo; imunidade.

\section{Introducción}

Durante la mayor parte de la historia de la humanidad, casi todas las madres han alimentado a sus niños de forma normal, natural y sin aspavientos: amamantando. Casi todas las sociedades tradicionales en África, Asia y América Latina, han tenido un excelente conocimiento local sobre la lactancia, aunque las prácticas han variado de una cultura a otra. ${ }^{1}$

El famoso pediatra Paul Gyorgy dijo: la leche de vaca es la mejor para los terneros y la leche humana es la mejor para los bebés humanos. Nadie puede negar lo cierta que es esa afirmación.

Cada vez se reconoce más ampliamente que toda madre, tiene el derecho de amamantar a su bebé y que cada niño tiene el derecho de recibir leche materna. Cualquier obstáculo en la alternativa de recibir leche materna, es un incumplimiento de estos derechos; aunque en la mayoría de los 
países, haya muchos bebés que no reciben leche materna o que reciben leche materna durante un período relativamente corto. ${ }^{1}$

Hace más de dos décadas, que en la literatura se viene indicando la importancia de la lactancia materna (LM). Diversos autores coinciden en señalar que se trata de un acto fisiológico, instintivo, herencia biológica adaptativa de los mamíferos y particular de cada especie. ${ }^{2}$

La Organización Mundial de la Salud (OMS), declara que es un hábito ligado íntimamente a la supervivencia de la especie humana desde tiempo inmemorial, y que como mamífero que es, la cría humana precisa de la leche de su madre para su supervivencia, puesto que sin ella, fallecería inexorablemente. ${ }^{3}$

A partir de lo anterior, la OMS y la Organización de las Naciones Unidas (ONU), a través del Fondo de las Naciones Unidas para la Infancia (Unicef), han promovido fuertemente la lactancia materna exclusiva hasta los seis meses de vida, y como alimentación complementaria, hasta los dos años de vida del niño. Sin embargo, a nivel mundial, únicamente el 35\% de los bebés son amamantados durante sus primeros cuatro meses de vida. Situación que aumenta el riesgo de enfermedades en los lactantes, ya que la leche maternizada o de fórmula no proporciona la misma protección inmunológica de la leche materna. ${ }^{4}$

Autores como Carrasco y Corvalán, manifiestan que a pesar de la importancia de la lactancia materna exclusiva para la salud y desarrollo de los niños, esta no ha logrado mantenerse dentro de los períodos recomendados mundialmente por la OMS y la Unicef. ${ }^{5}$

Situación que genera mucha preocupación, puesto que el descuido en la lactancia natural exclusiva durante los primeros seis meses de vida, representa un factor de riesgo importante para el desarrollo de morbilidad y mortalidad del lactante y del niño. ${ }^{4}$

Con referencia a lo anterior, la alimentación del niño menor de seis meses basado en leche materna, juega un rol protagónico en la relación madre-niño, mas no solamente percibido desde el lado afectivo, sino en variaciones de la composición corporal tanto de la madre como del niño y especialmente sobre su desarrollo psicomotor y su fortalecimiento inmunitario. ${ }^{5}$ 


\section{Lactancia materna e inmunidad}

Si se descubriera una vacuna o sustancia, que fuera capaz de prevenir miles de muertes infantiles, que fuera barata y además se pudiera administrar por vía oral, sería considerado como algo revolucionario en el campo de la salud infantil. Pues bien esta vacuna, la tenemos al alcance de todos, existe desde tiempos inmemoriales y es la leche materna. ${ }^{6}$

Hoy en día se ha podido demostrar científicamente, lo que ya era patrimonio de la sabiduría popular y es que la madre protege al niño de las infecciones a través de la leche. En el momento del nacimiento, en el cual el bebé ya puede mamar, la madre produce para él la primera leche, llamada calostro. El calostro es un líquido amarillento espeso, contiene gran cantidad de proteínas y minerales y posee menos grasa e hidratos de carbono (lechosa) que la leche de Continuación. ${ }^{6}$

Entre estas proteínas están las Inmunoglobulinas (Ig), que son anticuerpos que defienden contra las infecciones. ${ }^{6}$

Hay cinco tipos de Ig y el calostro las contiene todas. La que más abunda es la Ig A secretoria, que es un tipo de Ig A llamada secretoria. Esta Ig A, está formada por dos moléculas; Ig A y un factor secretorio que además de ser transportador, impide que las moléculas sean atacadas por los jugos gástricos. Contiene también gran cantidad de Ig D e Ig E. ${ }^{6}$

Estos Anticuerpos (Ac), están muy polarizados contra los agentes patógenos del entorno inmediato. La madre sintetiza anticuerpos cuando ingiere, inhala o entra en contacto con alguna de estas bacterias patógenas y traspasa al recién nacido, los Ac a través de la leche. Estos Ac no están dirigidos contra las bacterias beneficiosas del intestino, que sirven para arrinconar y defender al bebé de la otras bacterias patógenas. Cabe la posibilidad de que las inmunoglobulinas, además de proteger la mucosa intestinal y respiratoria protegen también el resto de las mucosas. En los países de África y Medio Oriente las madres aplican su leche en los ojos de los bebés para tratar las conjuntivitis. ${ }^{6}$

Otro factor humoral del calostro, es la lactoferrina que fija el hierro de manera reversible. Este hierro lo necesitan las bacterias para su crecimiento y la lactoferrina impide que esté a disposición de las bacterias, ejerciendo así un efecto bacteriostático, similar al de algunos antibióticos. ${ }^{6}$ 
También contiene:

- Proteína fijadora de la B12, que reduce la cantidad de B12 disponible para el crecimiento bacteriano.

- Oligosacáridos, que impiden que las bacterias penetren en el interior de las células.

- Mucinas, que se unen a bacterias, virus y ayudan a eliminarlos del organismo.

- Factor bífido, que promueva el crecimiento de lactobacilos bífidus, que son bacterias favorecedoras e inocuas que impiden el crecimiento de otras bacterias dañinas.

- Interferon gamma, potencia la actividad antimicrobiana de las células inmunitarias. Lisosomas que destruyen las bacterias al disgregar sus paredes celulares.

- El calostro, contiene también factores celulares: macrófagos y linfocitos. Los macrófagos hacen de presentadores de antígenos. Los linfocitos pueden ser B o T. Los B son los productores de Ac y los T destruyen directamente las células infectadas. ${ }^{6}$

Factores humorales: inmunoglobulinas, lactoferrina, proteína fijadora de la B12, oligosacáridos, mucinas, factor bífido, interferón gamma, lisosomas.

Factores celulares: Macrófagos, Linfocitos.

La Organización Mundial de la Salud (O.M.S.) recomienda en los países subdesarrollados, que la lactancia materna exclusiva se prolongue hasta los nueve meses, pues se ha comprobado que los bebés están más protegidos contra las infecciones.

Después del calostro viene la leche de transición y luego la leche madura, ambas van aumentando su contenido en hidratos de carbono y grasas, pero el contenido de factores inmunológicos sigue siendo muy elevado. ${ }^{6}$

El calostro y la leche materna, no solo defienden de enfermedades vacunables (varicela, sarampión, difteria, etc.) sino también de otras enfermedades no vacunables como (otitis, faringitis etc.) en general de las enfermedades respiratorias tan frecuentes en los niños. ${ }^{6}$ 
Como sistema para alimentar al niño en los primeros meses de la vida, la leche materna ha probado su eficacia a lo largo de las generaciones y ha sido por ella que la humanidad ha subsistido. $^{7}$

\section{La leche materna: una vacuna de amplio espectro}

Para todos son conocidas las ventajas de la leche materna, para la alimentación del lactante; sin embargo, para muchos profesionales éstas se circunscriben a su mayor digestibilidad, su esterilidad, y que resulta más económica, cuando lo cierto es que no menos importante es la posibilidad de ayudar a desarrollar el cuerpo y la inteligencia de los niños; contiene aminoácidos que necesita el normal desarrollo del cerebro; los protege contra las infecciones y enfermedades y contiene las cantidades necesarias de vitaminas (fósforo, hierro, proteínas, grasas y azúcares). La leche de la madre es la mayor protección para el niño contra las diarreas y la deshidratación, las infecciones respiratorias, el estreñimiento, los cólicos y las alergias, las enfermedades de la piel, el sarampión, el cólera y otras. Para las madres, la lactancia facilita e incrementa el amor a su hijo. Amamantar les brinda tranquilidad porque los niños se enferman menos. ${ }^{7}$

Por otro lado, la leche materna debe ser considerada la primera vacuna que recibe el niño y que es capaz de protegerlo, de un elevado número de infecciones frecuentes que lo amenazan durante el primer año de vida, por los anticuerpos que contiene y otros componentes inmunológicos, tanto humorales como celulares, que confirman su función protectora contra virus, bacterias y parásitos. $^{7}$

No son pocos los que plantean que el avance de la técnica y la alimentación han librado a la mujer de la ardua tarea de lactar a sus hijos, al crear fórmulas de leche capaces de cubrir las capacidades de nutrientes en los niños pequeños. Sin embargo, los que lo afirman pretenden olvidar que lactar a un niño, es de las relaciones más gratificantes que puede experimentar una mujer y que la leche humana y el proceso de alimentación natural, son claramente superiores a las demás formas de alimentación, cualesquiera que sean las condiciones socioeconómicas, culturales o higienicodietéticas de los lactantes. $^{7}$

\section{Un bebé alegre y feliz, es un bebé fuerte y bien preparado}

Durante la lactancia como durante el parto, se pone en juego un complejo mecanismo neurohormonal, que influye directamente sobre la inmunidad del bebé. ${ }^{6}$ 
En el momento del parto se libera gran cantidad de oxitocina (la hormona del amor), que induce comportamientos maternales y bienestar en la mujer. Junto con la oxitocina se liberan gran cantidad de endorfinas. ${ }^{6}$

Todo esto ocurre también durante la lactancia. A los pocos segundos de empezar el bebé a mamar, gran cantidad de oxitocina y endorfinas pasan al bebé a través de la leche materna. Estas endorfinas provocan un "cuelgue" de placer entre la madre y el bebé que es el sustrato fisiológico del vínculo materno infantil. ${ }^{6}$

Esta liberación de oxitocina y endorfinas, se da también durante el orgasmo. Se han medido niveles en sangre de estas hormonas y son similares en estos tres acontecimientos de la vida sexual del hombre. ${ }^{6}$

Estas hormonas oxitocina y endorfinas, al producir bienestar y placer tienen un efecto directo sobre la inmunidad, potenciándola tanto en su faceta pasiva como activa. ${ }^{6}$

En una investigación realizada por González $\mathrm{Méndez}^{7}$, sobre la lactancia materna se obtuvo que las mujeres entre 20 y 34 años de edad, amas de casa, casadas con el nivel secundario y con un solo hijo, fueran las que lograron una mayor efectividad en la lactancia materna. Entre las causas de abandono precoz de la lactancia se encontró la hipogalactia y como causa más frecuente en estos niños se observaron las infecciones respiratorias agudas.

En un estudio llevado a cabo en 2013 en la Fundación Humanitaria Pablo Jaramillo, los resultados reflejan que el nivel de conocimiento, actitud y técnica sobre la lactancia materna, en madres adolescentes fue calificado de malo (nivel 1). ${ }^{8}$

La protección, la promoción y el apoyo de la lactancia es una prioridad de desarrollo de cualquier país. Su logro o no tiene implicaciones de órdenes sociales, económicos y ambientales de gran magnitud y en plazos de tiempo distintos.

En Ecuador en el 2012, se incrementó la lactancia materna exclusiva al $43 \%$ y que una de las 8 metas incluidas en el Plan Nacional del Buen Vivir 2013-2017, es el incremento al 64\% de la lactancia materna exclusiva. El MSP fomenta el apego precoz entre la madre y el recién nacido; salas de apoyo a la lactancia materna en lugares de trabajo; bancos de leche humana (al momento existen 7 centros en el país). ${ }^{9}$ 
En este mismo orden y dirección, los últimos datos que recoge la Encuesta Nacional de Salud y Nutrición (ENSANUT) publicada en el año 2014, señalan que el 50\% de las madres en el país inician con lactancia materna exclusiva; pero lastimosamente la duración promedio es de 2.4 meses, cuando la recomendación es mínimo hasta los seis meses, como lactancia materna exclusiva. Esos datos señalan que no existe una estructura bien definida de cómo proteger la lactancia materna exclusiva del recién nacido hasta los seis meses. ${ }^{10}$

A través de la iniciativa mundial sobre tendencias de la lactancia materna (WBTi por sus siglas en inglés), se realizó entre septiembre y diciembre del 2015, una evaluación de las fortalezas y debilidades de las políticas y programas relacionados con alimentación de lactantes y niños pequeños. Se analizaron 15 indicadores, 10 cualitativos y 5 cuantitativos. El primer reporte se publicó en el año 2008 y el resultado fue un cumplimiento del 65,5/150; después del análisis del 2015, la calificación alcanzó 74/150. ${ }^{10}$

De acuerdo con los razonamientos que se han venido realizando, la leche materna es el alimento ideal para los recién nacidos y los lactantes: aporta todos los nutrientes necesarios, es inocua y no requiere preparación y contiene anticuerpos. Además, beneficia a las madres: ayuda a perder peso después del parto, reduce el riesgo de diabetes tipo 2, de cáncer de mama y de ovario, y disminuye el riesgo de anemia.

\section{Referencias bibliográficas}

1- Lactancia materna. Capítulo 7 [citado 8 abril 2016]. Disponible en: http://www.fao.org/docrep/006/w0073s/w0073s0b.htm

2- Rodríguez CR, Prieto ME, Payan M, Quesada MM. Intervención educativa sobre lactancia materna. AMC 2010; 14(3).

3- Barriuso L, De Miguel M, Sánchez M. Lactancia materna: factor de salud. Recuerdo histórico. Rev Anales Sis San. 2007; 30(3): 383-391.

4 Borre Ortiz, Yeis Miguel; Cortina Navarro, Carolina; González Ruíz, Gisela. Lactancia materna exclusiva: ¿la conocen las madres realmente?, revista cuidarte, 2014 [citado 8 abril 2016]; 5(2), pp. 723-730. Disponible en: http://www.redalyc.org/articulo.oa?id=359533181003 
5- Ricardo Sevilla Paz Soldán 1, 3, a, Lourder Zalles Cueto 1, 2, b, Walter Santa Cruz Gallardo 3. Lactancia materna vs nuevas fórmulas lácteas artificiales: evaluación del impacto en el desarrollo, inmunidad, composición corporal en el par madre/niño. 2011. Gac med bol 2011; 34 (1): 6-10.

6- Igual b. Lactancia materna e inmunidad. 2006 [citado 8 abril 2016]. Disponible en: http://www.holistika.net/parto_natural/lactancia_materna/lactancia_materna_e_inmunidad.asp

7- González Méndez Iraida, Pileta Romero Berenies. Lactancia materna. Rev Cubana enfermer. 2002 [citado 2016 mayo 29]; 18(1): 15-22. Disponible en: http://scielo.sld.cu/scielo.php?script=sci_arttext\&pid=S0864-03192002000100003\&lng=es

8- Guerrero Cisnero. J Vera J. Nivel de conocimiento sobre la lactancia materna en madres adolescentes 2013 [citado 2016 mayo 29]. Disponible en: dspace.uazuay.edu.ec/bitstream/datos/2778/1/09847.pdf

9- OMS. 2012. [citado 2016 mayo 29]. Disponible en: http://www.paho.org/ecu/index.php?option=com_content\&view=article\&id=985:msp-destacalactancia-materna-politica-fundamental-erradicacion-desnutricion-infantil\&Itemid=360

10- Herrera M E. Ecuador: indicadores en rojo en la alimentación del recién nacido e infante. 2016. [citado 2016 mayo 29]. Disponible en: http://laconversacion.net/2016/11/ecuadorindicadores-en-rojo-en-la-alimentacion-del-recien-nacido-e-infante/ 